\title{
ẢNH HƯỞNG CỦA MƯA ĐÂU MÙA TỚI Độ DÀY QUANG HỌC SOL KHÍ TẠI BẠC LIÊU
}

\author{
PHẠM XUÂN THÀNH, NGUYẼ̃N XUÂN ANH, LÊ VIÊT HUY \\ LÊ NHU QUÂN, HOÀNG HẢI SƠN, PHẠM LÊ KHƯƠNG \\ E-mail: pxthanh@igp-vast.vn \\ Viện Vật lý Địa cầu, Nhà A8, 18 Hoàng Quốc Việt, Cầu Giấy, Hà Nội
}

Ngày nhận bài: 09-11-2010

\section{Mở đầu}

Sol khí (aerosol) trong khí quyển là các hạt rắn hoặc lỏng tồn tại lơ lửng trong không khí. Sol khí trong khí quyển có nguồn gốc tự nhiên hoặc nhân tạo. Loại có nguồn gốc tự nhiên bao gồm: các hạt muối (từ đại dương), các bụi khoáng do gió đưa lên, từ núi lửa, từ thực vật, và các sản phẩm của các phản ứng khí tự nhiên. Loại có nguồn gốc nhân tạo do chất thải công nghiệp (khói, bụi,...), nông nghiệp, sản phẩm của các phản ứng khí [1]. Độ dày quang học sol khí (AOD: Aerosol optical depth) là đại lượng đặc trưng cho sự suy giảm của tia bức xạ mặt trời do hấp thụ và tán xạ của các phần tử sol khí tại điểm quan trắc so với giới hạn trên khí quyển.

Những thập kỷ gần đây, mức độ phát thải sol khí vào khí quyển ngày càng tăng liên quan đến quá trình phát triển công nghiệp của các quốc gia trên thế giới. Nồng độ các phần tử sol khí trong khí quyển tăng lên tác động trực tiếp tới sức khoẻ và đời sống con người do giảm chất lượng không khí, ngoài ra còn tác động gián tiếp thông qua ảnh hưởng tới thời tiết, khí hậu. Theo Lau K.-M. et al, 2008 [4], các phần tử sol khí tán xạ và hấp thụ bức xạ làm cho lớp khí quyển ấm lên và bề mặt trái đất lạnh đi (ảnh hưởng trực tiếp). Khi bề mặt trái đất lạnh hơn khí quyển phía trên, khí quyển trở nên ổn định (ảnh hưởng bán trực tiếp). Các phần tử sol khí làm tăng số hạt nhân ngưng kết hình thành hạt nước nhỏ hơn, dẫn đến tăng tán xạ và phản xạ của mây. Các hạt nước nhỏ làm hạn chế sự va chạm và liên kết, kéo dài thời gian tồn tại của mây và ngăn cản sự lớn lên của hạt nước trong mây tạo các hạt mưa (ảnh hưởng gián tiếp). Chung C.E. và cộng sự
2005 [2] chỉ ra rằng ảnh hưởng trực tiếp của sol khí làm giảm năng lượng bức xạ trung bình toàn cầu, tại giới hạn trên khí quyển $0.35 \mathrm{~W} / \mathrm{m}^{2}$, tăng trong lớp khí quyển $3.0 \mathrm{~W} / \mathrm{m}^{2}$, và giảm tại bề mặt trái đất $3.4 \mathrm{~W} / \mathrm{m}^{2}$. Trong vùng châu Á gió mùa, trung bình năm, năng lượng bức xạ trong khí quyển (mặt đất) có thể tăng (giảm) $10-20 \mathrm{~W} / \mathrm{m}^{2}$. Theo Ramanathan $\mathrm{V}$. et al, 2005 [7], màn mây nâu $\mathrm{ABCs}$ (Atmospheric Brown Clouds) cấu thành từ các chất ô nhiễm như các bon đen, các bon hữu cơ, tro, bụi và các chất hấp thụ như là sun fat, ngăn cản bức xạ mặt trời tới mặt đất có thể làm giảm $50 \%$ của sự nóng lên toàn cầu do tăng các khí nhà kính.

Ảnh hưởng trực tiếp của sol khí làm thay đổi phân bố năng lượng của khí quyển và bề mặt, thay đổi gradient áp suất theo phương ngang, tác động tới hoàn lưu gió mùa và làm thay đổi lượng mưa của một số nơi trên Trái Đất (Ramanathan V. et al, 2005 [7]; Lau K.-M., 2006 [5]; Zhang Y., et al, 2009 [11]). Ngược lại, dị thường hoàn lưu quy mô lớn liên quan đến sự thay đổi vận chuyển sol khí, điều chỉnh quá trình sa lắng khô và ướt, và thay đổi môi trường vật lý và hoá học của hỗn hợp sol khí. Bụi có thể được hoàn lưu quy mô lớn vận chuyển từ vùng sa mạc lân cận tới Ấn Độ (Lau K.-M., 2008 [4]). Những trận mưa rào mạnh trong mùa khô ảnh hưởng tới phổ độ dày quang học và đặc trưng kích thước của sol khí (Saha $\mathrm{A}$. and Moorthy K.K., 2004 [8]). Trong hội thảo quốc tế về “Ảnh hưởng của sol khí đến bức xạ và động năng của chu trình nước gió mùa" tổ chức từ ngày 31 tháng 7 đến ngày 4 tháng 8 năm 2006 tại Tây Tạng, Trung Quốc, các nhà khoa học thế giới đã khẳng định: Tương tác giữa sol khí - gió mùa là một thách 
thức mới đối với nghiên cứu khí hậu gió mùa (Lau K.-M., et al, 2008).

Ở Việt Nam, hướng nghiên cứu trên mới chỉ thực sự bắt đầu năm 2003, khi chúng ta có hai trạm quan trắc sol khí đầu tiên trong mạng trạm AERONET của NASA đặt tại Bạc Liêu và Bắc Giang. Những kết quả ban đầu thu được từ hoạt động của trạm đã được tác giả Nguyễn Xuân Anh và Lê Việt Huy đánh giá trong bài báo đăng trong Tuyển tập các công trình nghiên cứu vật lý địa cầu 2008 [1]. Gần đây, tác giả Hồ Thị Minh Hà và Phan Văn Tân, 2009 đã sử dụng mô hình RegCM3 để mô phỏng ảnh hưởng của carbon đen $(\mathrm{BC})$ lên khí hậu khu vực Đông Nam Á và Việt Nam. Kết quả cho thấy, tác động của $\mathrm{BC}$ lên lượng mưa thể hiện ở hệ số tương quan (HSTQ) âm trên khu vực bán đảo Đông Dương trong khi trên phía đông của Ấn Độ và Trung quốc, HSTQ dương [3].
Dựa trên chuỗi số liệu AOD của trạm sol khí Bạc Liêu và số liệu mưa từng giờ của trạm Khí tượng Bạc Liêu, chúng tôi xác định các trận mưa đầu mùa ghi được tại Bạc Liêu năm 2003; phân tích ảnh hưởng của mưa đầu mùa năm 2003 đến độ dày quang học và phân bố kích thước của các hạt sol khí tại Bạc Liêu.

\section{Cơ sở số liệu}

Nguồn số liệu được sử dụng trong nghiên cứu này bao gồm: 1) số liệu về độ dày quang học sol khí của trạm Bạc Liêu; 2) số liệu mưa từng giờ của trạm khí tượng Bạc Liêu; và 3) số liệu độ ẩm và gió của Trung tâm Quốc gia dự báo môi trường Mỹ/ Phòng năng lượng (NCEP/DOE-2). Trạm quan trắc sol khí Bạc Liêu nằm trong mạng trạm AERONET toàn cầu do Cơ quan Hàng không Vũ trụ Mỹ NASA thiết lập (hình 1). Thiết bị sử dụng là quang phổ kế tự động CIMEL 318 do Pháp chế tạo.

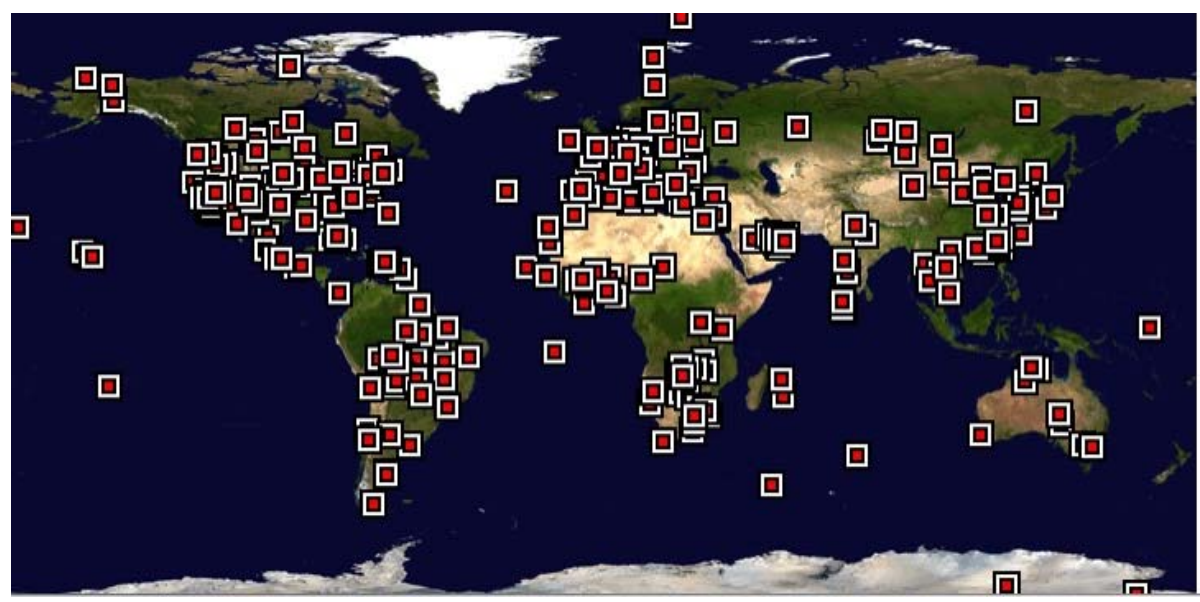

Hình 1. Mạng trạm quan sát sol khí toàn cầu (AERONET) của NASA

Thiết bị thực hiện hai phép đo cơ bản là trực xạ và tán xạ. Trực xạ đo ở 8 giải phổ: $340,380,440$, $670,870,940$ và $1020 \mathrm{~nm}$. Tán xạ được đo ở 4 dải phổ $(440,670,870$ và 1020 nm) với các góc tán xạ khác nhau. Phép đo được tiến hành trong 10 giây và lăp lại 3 lần (triplet). Thời gian đo được bắt đầu tự động khi khối lượng khí quyển (air mass) bằng 7 vào buổi sáng và kết thúc vào buổi chiều khi khối lượng khí quyển cũng bằng 7 . Từ chuỗi số liệu này, có thể tính được độ dày quang học sol khí, lượng hơi nước trong khí quyển và thông số Angstrom (thông số đặc trưng cho kích thước của hạt). Trạm sol khí Bạc Liêu được lắp đặt và vận hành từ ngày 10 tháng 3 năm 2003. Số liệu của trạm Bạc Liêu cũng như của các trạm khác trong mạng ARONET được phân cấp theo ba thế hệ : $1.0 ; 1.5$ và 2.0 . Trong nghiên cứu này, chúng tôi sử dụng thế hệ 2.0 - thế hệ số liệu có chất lượng đảm bảo nhất [1].

Số liệu mưa mặt đất được thu thập tại trạm Khí tượng Bạc Liêu (cách trạm sol khí khoảng 500m). Để đảm bảo tính chính xác khi xem xét ảnh hưởng của mưa tới độ dày quang học, chuỗi số liệu này được lấy theo từng giờ, kéo dài từ 1-1-2003 đến 12-2009 (trùng với thời gian quan sát sol khí). 
Số liệu độ ẩm tương đối và gió của NCEP/DOE2 được lấy tại nút lưới $10^{\circ} \mathrm{N} ; 105^{\circ} \mathrm{E}$ (nút lưới có khoảng cách gần nhất tới trạm Bạc Liêu), trên 10 mực độ cao $(1000,925,850,700,600,500,400$, 300,250 , và $200 \mathrm{hPa}$ ), từ ngày 26 tháng 4 đến 7 tháng 5 năm 2003. Nguồn số liệu này dùng để xây dựng profile gió và độ ẩm theo chiều cao, từ đó, xác định thời điểm bắt đầu mùa mưa năm 2003 tại Bạc Liêu và phân tích ảnh hưởng của gió và độ ẩm tới biến đổi của độ dày quang học sol khí.

\section{Sự bắt đầu mùa mưa tại Bạc Liêu năm 2003}

\subsection{Ngày bắt đầu gió mùa mùa hè-mùa mua trên khu vục Nam Bọ}

Theo quan điểm của nhiều nhà khí tượng trên thế giới, trong khu vực châu Á gió mùa, thời điểm bắt đầu gió mùa mùa hè thường trùng với thời điển bắt đầu mùa mưa. Để xác định thời điểm bắt đầu gió mùa mùa hè-mùa mưa (BĐGM-MM), các tác giả trên thế giới sử dụng nhiều phương pháp khác nhau: 1) thông qua sự thay đổi của hướng gió thịnh hành; 2) dựa vào lượng mưa, khi nó vượt ngưỡng nào đó; 3) tổ hợp giữa trường gió và mưa, hoặc giữa gió và hoạt động đối lưu [9].

Thời điểm BĐGM-MM trên khu vực Nam Bộ, điều kiện khí quyển có liên quan và khả năng dự báo thời điểm này, đã được chúng tôi nghiên cứu rất tỉ mỉ, và kết quả đã được trình bày trong [9]. Ở đây, chúng tôi xin trình bày vắn tắt cách xác định thời điểm BĐGM-MM cho khu vực Nam Bộ và kết quả tính cho 26 năm (từ 1979 đến 2004). Thời điểm BĐGM-MM trên khu vực Nam Bộ, được chúng tôi xác định dựa trên số liệu mưa ngày của 6 trạm (Bảo Lộc, Tây Ninh, Tân Sơn Nhất, Cần Thơ, Rạch Giá, Cà Mau) và số liệu gió mực $1000 \mathrm{hPa}$ tại 4 nút lưới $\left(105^{\circ} \mathrm{E}-107.5^{\circ} \mathrm{E} ; 10^{\circ} \mathrm{N}-12.5^{\circ} \mathrm{N}\right)$ của NCEP/DOE-2. Dựa trên chuỗi số liệu này, chúng tôi xác định : 1) Chỉ số mưa khu vực Nam Bộ : giá trị trung bình trượt 5 ngày của lượng mưa trung bình 26 năm của 6 trạm (hình 2, đường liền nét); 2) Vận tốc gió vĩ hướng trung bình 26 năm (hình 2 , đường đứt nét). Kết quả này cho thấy, sự chuyển từ mùa khô sang mùa mưa được đánh dấu bởi : 1) sự tăng đột ngột về lượng mưa từ $3 \mathrm{~mm} / \mathrm{ngày}$ trong tháng 4 sang $7 \mathrm{~mm} /$ ngày trong tháng $5 ; 2$ ) sự thay đổi hướng gió từ Đông-Nam (giá trị âm) sang Tây-Nam (giá trị dương). Trên cơ sở này, chúng tôi đưa ra tiêu chuẩn để xác định ngày bắt đầu gió mùa mùa hè- mùa mưa cho khu vực Nam Bộ là:

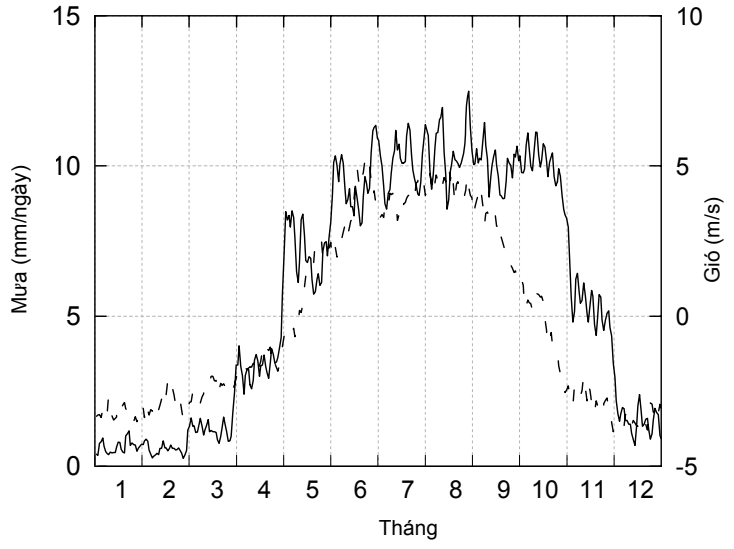

Hinh 2. Giá trị trung bình trượt 5 ngày của lượng mưa trung bình ngày 26 năm trên khu vực Nắc Bộ (đường liền nét) và Vận tốc gió vỹ hướng trung bình 26 năm của 4 nút lưới $\left(105^{\circ} \mathrm{E}-107.5^{\circ} \mathrm{E}\right.$; $\left.10^{\circ} \mathrm{N}-12.5^{\circ} \mathrm{N}\right)$.

(1) tổng lượng mưa ngày (sau khi trung bình trượt 5 ngày) phải vượt quá $5 \mathrm{~mm} /$ ngày và duy trì liên tục 5 ngày;

(2) tốc độ gió vỹ hướng phải lớn hơn $0,5 \mathrm{~m} / \mathrm{s}$.

Hai điều kiên trên cho phép xác định được đợt mưa đầu tiên của mùa mưa đủ để đánh dấu thời điểm BĐGM-MM trên khu vực Nam Bộ. Hơn nữa, nếu thêm điều kiện của Zhang Y., et al, 2002 [12] : "trong vòng 20 ngày tiếp theo ngày BĐGM-MM phải có ít nhất 10 ngày lượng mưa vượt quá $5 \mathrm{~mm} /$ ngày", thì kết quả tính ngày BĐGM-MM trên khu vực Nam Bộ từ 1979 đến 2004 không thay đổi ngoại trừ năm 1989.

Dựa theo tiêu chuẩn trên, chúng tôi đã tính ngày BĐGM-MM trên khu vực Nam Bộ, từ năm 1979 đến năm 2004 (bảng 1). Kết quả cho thấy, ngày $\mathrm{BĐGM-MM} \mathrm{trung} \mathrm{bình} 26$ năm là ngày 12 tháng 5 , với độ lệch chuẩn là 11.5 ngày. Năm mùa mưa đến sớm nhất là năm 1979 (ngày 19 tháng 4), và năm muộn nhất là năm 1993 (ngày 9 tháng 6). Kết quả này phù hợp với kết quả của các tác giả thế giới xác định ngày BĐGM-MM cho khu vực Đông Dương: Qian and Lee, 2000 [6] (từ ngày1 đến 15 tháng 5); Wang and LinHo, 2002 [10] (từ ngày 6 đến 10 tháng 5), và của Zhang Y., et al, 2002 (ngày 9 tháng 5).

\subsection{Mưa đầu mùa năm 2003 tại trạm Bạc Liêu}

Hình 3 biểu diễn lượng mưa ghi được tại trạm Bạc Liêu từ ngày 23 tháng 4 (trước ngày BĐGM- 
MM trung bình tại Nam Bộ 20 ngày) đến ngày 22 tháng 5 năm 2003. Tại thời điểm bắt đầu gió mùa mùa hè - mùa mưa năm 2003 trên khu vực Nam Bộ (bảng 1), ngày 4 tháng 5 , trạm Bạc Liêu ghi được lượng mưa $5,5 \mathrm{~mm}$. Trước đó, ngày 3 tháng 5 ghi được $7,5 \mathrm{~mm}$ và ngày 1 tháng 5 ghi được $4 \mathrm{~mm}$.

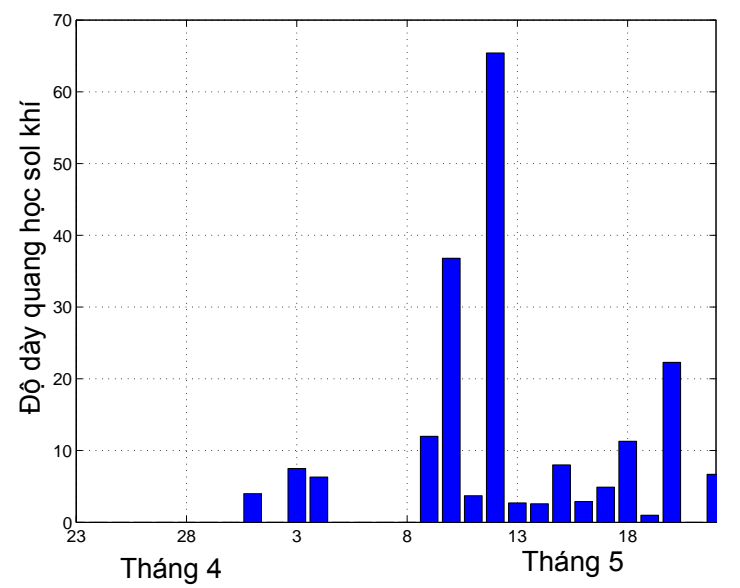

Hình 3. Lượng mưa ghi được tại trạm Bạc Liêu từ ngày 23 tháng 4 đến 22 tháng 5

Bảng 1: Ngày BĐGM-MM trên khu vực Nam Bộ từ 1979 đến 2004

\begin{tabular}{|c|c|c|c|c|c|}
\hline \multirow{2}{*}{ Năm } & \multicolumn{2}{|c|}{$\begin{array}{l}\text { Thời điểm } \\
\text { BĐGM-MM }\end{array}$} & \multirow{2}{*}{ Năm } & \multicolumn{2}{|c|}{$\begin{array}{l}\text { Thời điểm } \\
\text { BĐGM-MM }\end{array}$} \\
\hline & Ngày & Tháng & & Ngày & Tháng \\
\hline 1979 & 19 & 4 & 1992 & 7 & 5 \\
\hline 1980 & 19 & 5 & 1993 & 9 & 6 \\
\hline 1981 & 11 & 5 & 1994 & 3 & 5 \\
\hline 1982 & 1 & 5 & 1995 & 3 & 5 \\
\hline 1983 & 12 & 5 & 1996 & 1 & 5 \\
\hline 1984 & 5 & 5 & 1997 & 4 & 5 \\
\hline 1985 & 25 & 5 & 1998 & 25 & 5 \\
\hline 1986 & 11 & 5 & 1999 & 23 & 4 \\
\hline 1987 & 16 & 5 & 2000 & 2 & 5 \\
\hline 1988 & 21 & 5 & 2001 & 13 & 5 \\
\hline 1989 & 8 & 5 & 2002 & 14 & 5 \\
\hline 1990 & 16 & 5 & 2003 & 4 & 5 \\
\hline \multirow[t]{2}{*}{1991} & 8 & 6 & 2004 & 10 & 5 \\
\hline & & & TB & 12 & 5 \\
\hline
\end{tabular}

Để có thêm chi tiết cho sự bắt đầu mùa mưa năm 2003, chúng tôi xây dựng profile gió và độ ẩm theo chiều cao tại nút lưới $10^{\circ} \mathrm{N}$ và $105^{\circ} \mathrm{E}$ (nút lưới gần trạm Bạc Liêu nhất), cho các ngày từ 26 tháng 4 đến 7 tháng 5 (hình 4 và 5 ). Kết quả cho thấy, từ ngày 27 đến ngày 1 tháng 5 , gió ở mặt đất có hướng Đông $\mathrm{Bắc}(\mathrm{U}<0 ; \mathrm{V}<0)$, sang ngày 2 tháng 5 gió chuyển sang đông nam $(\mathrm{U}<0 ; \mathrm{V}>0)$, ngày 3 tháng 5 gió chuyển sang hướng tây nam $(U>0$; $\mathrm{V}>0$ ) và duy trì ổn định đến ngày 7 . Độ ẩm tương đối trên mực $500 \mathrm{hPa}$ trước ngày 2 tháng 5 đều nhỏ hơn $40 \%$ (hình 5 ). Ngược lại, các ngày 3,4 và 5 tháng 5 độ ẩm trên độ cao này vượt quá $60 \%$. Như vậy, cả trường gió và trường độ ẩm đều có biểu hiện của sự chuyển mùa và những trận mưa ngày 1 , 3 và 4 tháng 5 chính là trận mưa đầu mùa năm 2003 ghi được tại trạm Bạc Liêu.
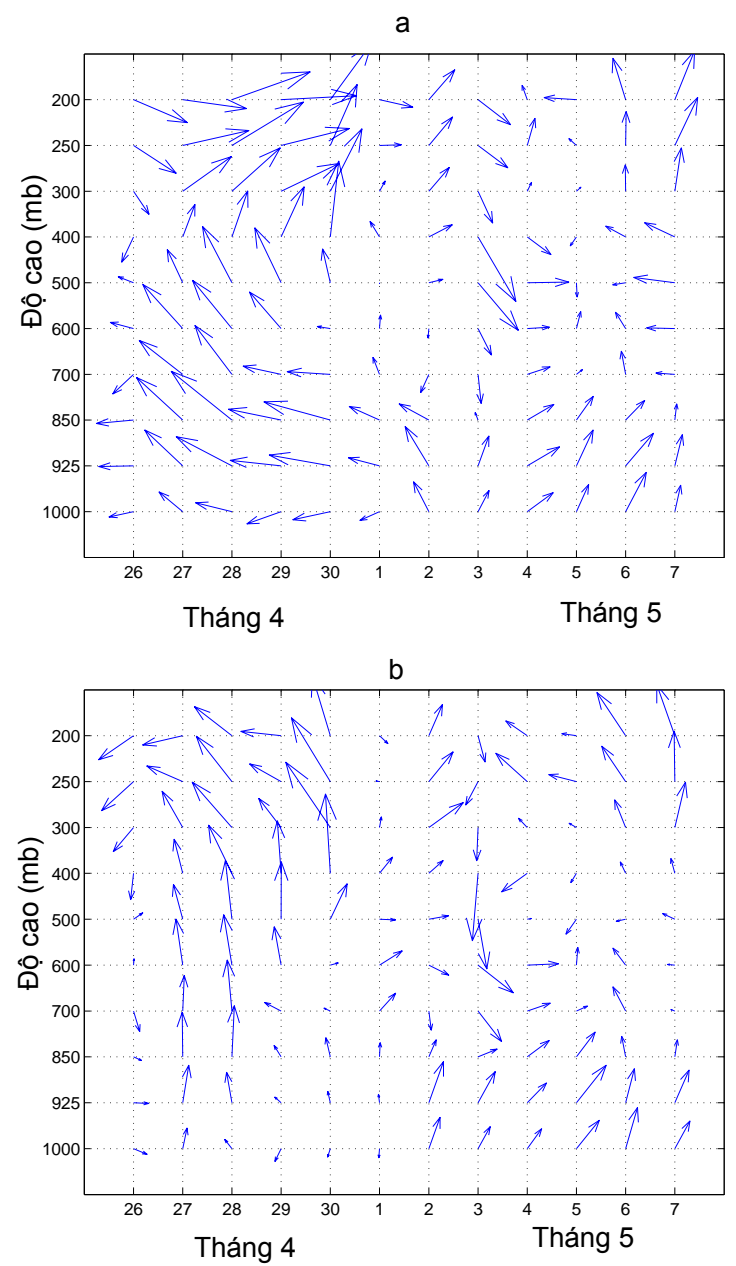

Hình 4. Profile tốc độ gió thành phần thẳng đứng và vỹ hướng $(\mathrm{a})$, thành phần thẳng đứng và kinh hướng (b) tại vị trí $10^{\circ} \mathrm{N}$ và $105^{\circ} \mathrm{E}$ xung quanh thời điểm BĐGM-MM tại trạm Bạc Liêu, (số liệu của NCEP/DOE-2) 
a

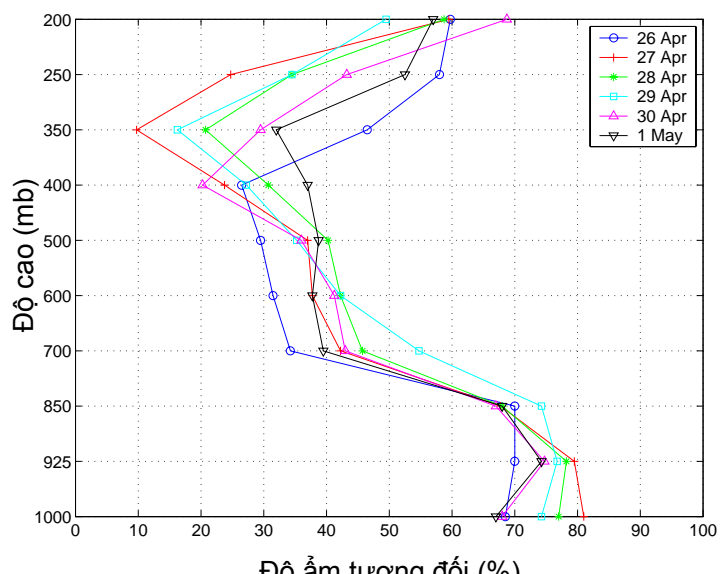

b

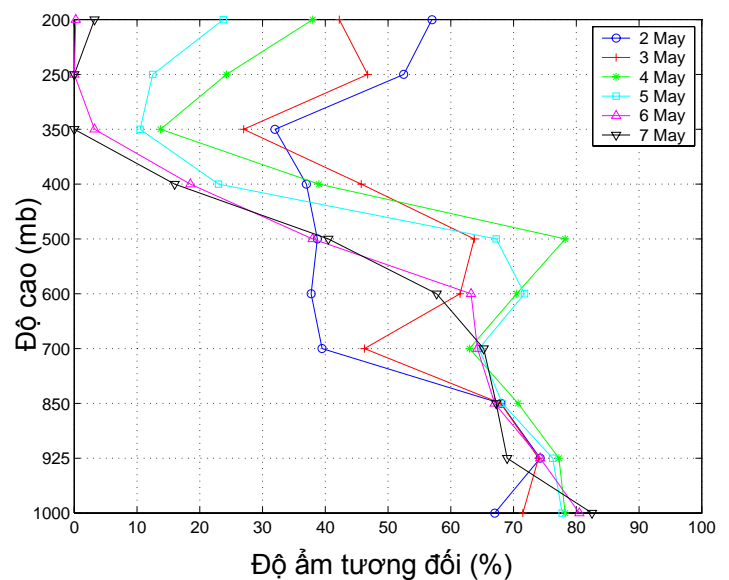

Hình 5. Profin độ ẩm theo chiều cao tại vị trí $10^{\circ} \mathrm{N}$ và $105^{\circ} \mathrm{E}$ xung quanh thời điểm $\mathrm{BĐGM-MM}$ tại trạm Bạc Liêu, (số liệu của NCEP/DOE-2)

\section{4. Ảnh hưởng của mưa đầu mùa tới độ dày quang học sol khí}

\subsection{Sỵ suy giảm của AOD sau trận mưa đầu mùa năm 2003}

Quá trình các phần tử sol khí trở lại mặt đất diễn ra trong 2 trường hợp: 1) sa lắng khô và 2) sa lắng ẩm. Tất nhiên, sa lắng ẩm có ảnh hưởng nhiều hơn bởi vì tốc độ rơi của hạt nước mưa lớn hơn nhiều tốc độ sa lắng của các hạt sol khí. Sa lắng ẩm bao gồm hai hình thức: i) các phần tử sol khí trở thành hạt nhân ngưng kết để hình thành mây và các hạt nước mưa hoặc bị dính vào hạt nước mây, sau đó di chuyển cùng với hạt nước mưa (quá trình này diễn ra trong mây), và ii) các phần tử sol khí bị rửa trôi (quá trình diễn ra dưới chân mây), mà các hạt sol khí bị cuốn bởi các hạt nước mưa. Sa lắng ẩm góp phần quan trọng giới hạn sự tồn tại của các hạt sol khí tại lớp bề mặt và khí quyển tầng thấp, đặc

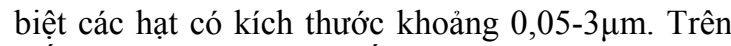
thế giới người ta đã tiến hành nghiên cứu mô phỏng về quá trình sa lắng của các phần tử sol khí trong mây và dưới mây; đo đạc ngoài hiện trường; và nghiên cứu trong phòng thí nghiệm. Những nghiên cứu này cho thấy sự sa lắng ẩm của các phần tử sol khí phụ thuộc vào phân bố kích thước và profile theo chiều cao của sol khí, tỷ lệ mưa, và phân bố kích thước của hạt mưa [8].

Trong phần này, chúng tôi trình bày ảnh hưởng của mưa tới độ dày quang học sol khí quan sát được tại Bạc Liêu từ ngày 26 tháng 4 đến 7 tháng 5 năm 2003. Trong khoảng thời gian này, tại trạm
Bạc Liêu ghi được ba trận mưa: trận thứ nhất, ngày 1 trong khoảng 11-13h với lượng mưa $4 \mathrm{~mm}$; trận thứ hai từ $20-21 \mathrm{~h}$ ngày 3 với lượng $7,5 \mathrm{~mm}$; và trận thứ 3 từ $3-5 \mathrm{~h}$ ngày 4 với lượng $5,5 \mathrm{~mm}$. Như đã trình bày ở trên, đây là những trận mưa đầu mùa năm 2003. Từ ngày 26 tháng 4 đến 7 tháng 5 năm 2003, có 9 ngày ghi được độ dày quang học sol khí với tổng số 148 lần đo. Số liệu mưa và độ dày quang học sol khí trong khoảng thời gian trên được trình bày trong hìn 6 .

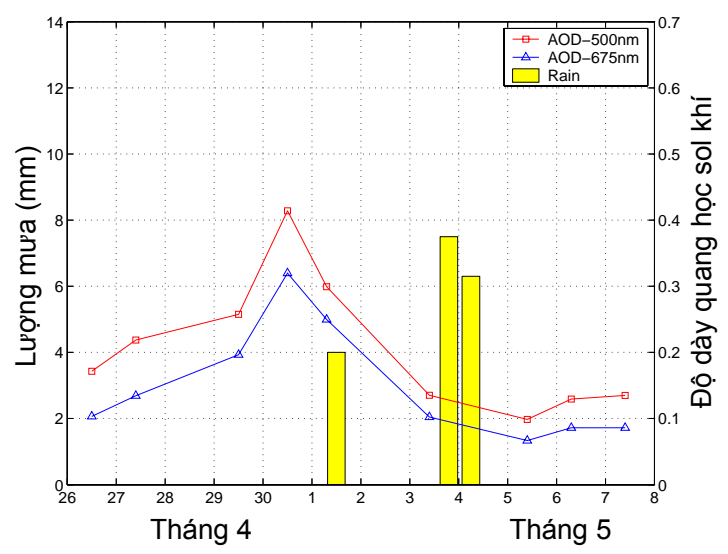

Hình 6. Thay đổi của độ dày quang học sol khí (nét liền chấm tam giác); tổng lượng mưa

(hình khối) tại trạm Bạc Liêu xung quanh thời điểm BĐGM-MM

Phân tích sự biến đổi theo thời gian của AOD và lượng mưa (hình 6 ) cùng với gió và độ ẩm (hình 4 và 5$)$, ta thấy: từ ngày 27 đến ngày 30 , gió ở mặt 
đất có hướng Đông Bắc $(\mathrm{U}<0 ; \mathrm{V}<0)$, thăng lên ở tất cả các độ cao (hình 4), độ ẩm tương đối trên mực $500 \mathrm{hPa}$ thấp, chỉ xâp xỉ 40\% (hình 5), trời không mưa, AOD tại bước sóng 500nm tăng chậm, từ 0.17 trưa ngày 26 đến 0,22 trưa ngày 27 và 0,26 lúc $12 \mathrm{~h}$ ngày 29 . Tiếp theo, AOD tăng nhanh và đạt cực đại vào 0,41 sáng ngày 30 tháng. Ngày 1 tháng 5 , gió mặt đất vẫn còn hướng Đông nhưng đã suy yếu, dòng thăng ở trên cao cũng yếu đi, buổi sáng $\mathrm{AOD}$ giảm còn 0,31 và sau trận mưa lúc giữa trưa, $A O D$ tiếp tục giảm mạnh. Sang ngày 3 và 4 gió tại mặt đất chuyển sang hướng Tây Nam $(U>0$; $\mathrm{V}>0$ ), độ ẩm tương đối trên tại mực $500 \mathrm{hPa}$ lớn hơn $60 \%$, $\mathrm{AOD}$ đo được ngày 3 là 0,13 . Sau trận mưa đêm ngày 3 và sáng ngày $4, \mathrm{AOD}$ giảm xuống cực tiểu của đợt $(0,10)$. Đến ngày 6 và 7 , độ ẩm trên mực $500 \mathrm{hPa}$ lại giảm xuống $40 \%$, trời không mưa, và $\mathrm{AOD}$ bắt đầu tăng nhẹ. Như vậy, sau 3 trận mưa, độ dày quang học sol khí giảm từ 0,4 xuống 0,10 , chứng tỏ mưa đã làm giảm đáng kể giá trị của độ dày quang học sol khí.

\subsection{Anh hưởng của mưa đầu mùa năm 2003 tới phân bố kích thước của phần tử sol khí}

Mưa không chỉ làm giảm độ lớn của $\mathrm{AOD}$ mà còn ảnh hưởng tới phân bố kích thước của các phần tử sol khí. Để tìm hiểu điều này, chúng tôi tiến hành tính các thông số Angstrom. Độ dày quang học, bước sóng và độ vẩn đục khí quyển liên quan với nhau bằng công thức Angstrom như sau:

$$
\tau=\beta \cdot \lambda^{-\alpha}
$$

Ở đây, $\beta$ là hệ số Angstrom, $\lambda$ bước sóng tính bằng micrômét, và $\alpha$ số mũ Angstrom. Hệ số $\alpha$ và $\beta$ phụ thuộc vào bước sóng, và có thể sử dụng để mô tả kích thước của phần tử sol khí và độ vẩn đục của khí quyển.

Với hai bước sóng khác nhau, ta có:

$$
\begin{aligned}
\tau_{1} & =\beta \cdot \lambda_{1}^{-\alpha} \\
\tau_{2} & =\beta \cdot \lambda_{2}{ }^{-\alpha}
\end{aligned}
$$

và

$$
\tau_{1} /\left(\lambda_{1}^{-\alpha}\right)=\tau_{2} /\left(\lambda_{2}^{-\alpha}\right)
$$

cuối cùng rút ra:

$$
\alpha=\ln \left(\tau_{1} / \tau_{2}\right) / \ln \left(\lambda_{2} / \lambda_{1}\right)
$$

Trong khí quyển tự nhiên, $\alpha$ biến đổi trong khoảng từ 0.5 đến 2.5 , với giá trị trung bình $\alpha=1.3 \pm 0.5$. Khi giá trị của $\alpha$ lớn, giá trị $\tau$ tương ứng với bước sóng lớn, nhỏ hơn nhiều giá trị $\tau$ tương ứng với bước sóng nhỏ, hàm ý một khí quyển có tỷ lệ cao của các phần tử có kích thước nhỏ so với phần tử có khích thước lớn $(\mathrm{r}>0.5 \mu)$. Khi $\tau$ của bước sóng lớn tiệm cận $\tau$ của bước sóng nhỏ, thì các phần tử lớn chiếm ưu thế và giá trị của $\alpha$ sẽ nhỏ [13].

Hệ số $\beta$ sẽ được tính cho từng bước sóng:

$$
\beta=\tau_{1} \cdot \lambda_{1}{ }^{\alpha}=\tau_{2} \cdot \lambda_{2}{ }^{\alpha}
$$

ở đây, $\lambda$ được tính bằng micrômét $(500 \mathrm{~nm}=$ $0.500 \mu$ ). Giá trị của $\beta<0.1$ khí quyển tương đối sạch và $\beta>0.2$ khí quyển vẩn đục.

Để đánh giá ảnh hưởng của mưa tới phân bố kích thước của các phần tử sol khí tại trạm Bạc

\begin{tabular}{|c|c|c|c|c|c|}
\hline Ngày & $\alpha$ & $\beta$ & Ngày & $\alpha$ & $\beta$ \\
\hline $26-04-2003$ & 1.69 & 0.05 & $03-05-2003$ & 0.93 & 0.07 \\
\hline $30-04-2003$ & 0.86 & 0.23 & $05-05-2003$ & 1.31 & 0.04 \\
\hline
\end{tabular}
Liêu, chúng tôi xây dựng đồ thị phân bố phổ $\mathrm{AOD}$ của các ngày 26,30 tháng 4 và 3,5 tháng 5 (hình 7) và tính toán hệ số $\alpha$ và $\beta$ cho bước sóng $500 \mathrm{~nm}$ cho các ngày này (bảng 2 ).

Bảng 2. Thông số Angstrom

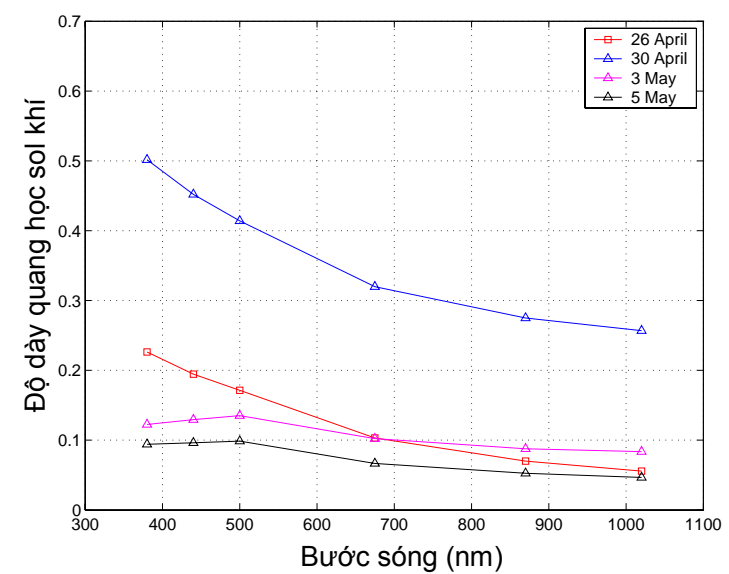

Hình 7. Biến đổi phổ độ dày quang học sol khí xung quanh thời điểm BĐGM-MM

Kết quả cho thấy: ngày 26 , giá trị $\tau$ tại bước sóng $1020\left(\tau_{1020}=0.056\right)$ nhỏ hơn rất nhiều so với $\tau$ tại bước sóng $380\left(\tau_{380}=0.226\right), \alpha$ có giá trị lớn $(\alpha=1,69)$, tỷ lệ của các hạt nhỏ so với các hạt lớn cao, khí quyển tương đối sạch ( $\beta=0.05$ ). Sang ngày 30 , tình hình đảo ngược hoàn toàn, giá trị $\tau$ tại bước sóng $1020\left(\tau_{1020}=0.257\right)$ nhỏ bằng một nửa so với $\tau$ tại bước sóng $380\left(\tau_{380}=0.502\right)$, $\alpha$ có giá trị nhỏ $(\alpha=0,86)$, các hạt kích thước lớn chiếm ưu thế, khí quyển vần đục $(\beta=0.23)$. Sự tăng mạnh của các 
hạt có kích thướng lớn trong ngày 30 so với ngày 26 , có thể do sự duy trì dòng thăng từ ngày 27 đến 30 đã cuốn các hạt có kích thước lớn lên độ cao hơn. Sau trận mưa thứ nhất số hạt có kích thước lớn giảm hẳn ( $\beta$ giảm từ 0,23 xuống 0,07$)$. Sau trận mưa ngày 3 và 4 , số hạt lớn tiếp tục giảm ( $\beta$ giảm từ 0,07 xuống 0,$04 ; \alpha$ tăng từ 0,93 đển 1,31$)$, không khí trở thành không khí sạch. Như vậy, các hạt sol khí có kích thước lớn bị cuốn trôi ngay từ những trận mưa đầu tiên, kể cả khi trận mưa không lớn. Kết quả này rất phù hợp với kết luận của Saha and Moorthy, 2004 nghiên cứu tại Ấn Độ.

\subsection{Anh huởng của mua đầu mùa tới $A O D$}

Để thấy được ảnh hưởng của mưa đầu mùa đến AOD, chúng tôi so sánh trị số AOD tại bước sóng $500 \mathrm{~nm}$ trung bình trong một tháng đầu mùa mưa và một tháng cuối mùa khô. Thời gian đầu mùa mưa được tính từ ngày 23 tháng 5 (sau thời điểm bắt đầu mùa mưa trung bình (12 tháng 5 ) cộng với độ lệch chuẩn (11.6 ngày)) đến ngày 22 tháng 6 . Tương tự, thời gian cuối mùa khô được tính từ ngày 1 tháng 4 đến ngày 30 tháng 4 . Kết quả, trong tháng đầu mùa mưa, từ năm 2003 đến 2009, có 685 lần quan sát được $\mathrm{AOD}$, và giá trị trung bình đạt được là 0.197 . Trong tháng cuối mùa khô, các giá trị tương ứng là 1058 lần và 0.223 . Sự sai khác của AOD giữa thời gian đầu mùa mưa và cuối mùa khô được là 0.025 .

Ảnh hưởng của mưa đầu mùa tới AOD góp phần đáng kể trong sự chênh lệch $\mathrm{AOD}$ giữa mùa khô và mùa mưa như biểu diễn trong hình 8 .

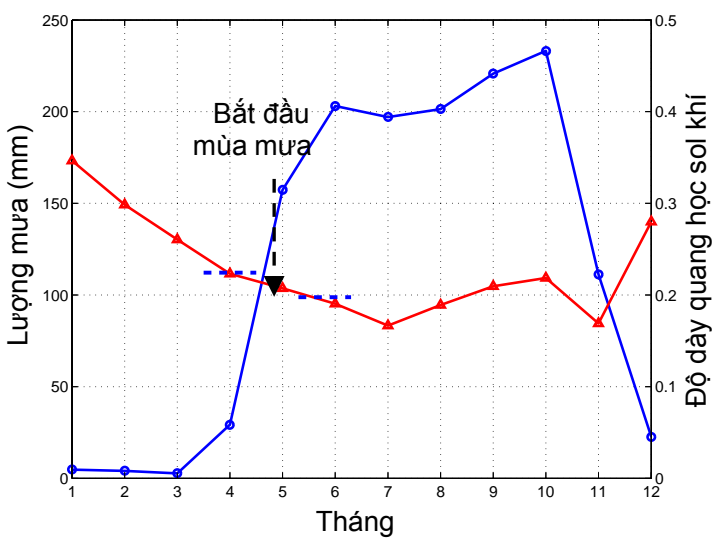

Hình 8 . Biến trình năm của độ dày quang học sol khí (nét liền chấm tam giác) và của lượng mưa (nét liền, chấm tròn) tại trạm Bạc Liêu, tính trung bình từ 2003 đến 2009 . Đường đứt nét là giá trị trung bình $\mathrm{AOD}$ trong một tháng trước và sau khoảng thời gian bắt đầu mùa mưa
Tính trung bình, trong 4 tháng mùa khô (tháng $12,1,2$ và 3 , AOD đạt 0.29 , và trong 4 tháng mùa mưa (tháng $6,7,8$, và 9 ), AOD là 0.19 . Sự chênh lệch giữa mùa khô và mùa mưa là 0.10 .

\section{Kết luận}

Mục đích của bài báo này là xác định ảnh hưởng của mưa đầu mừa năm 2003 đến độ dày quang học sol khí và phân bố kích thước các hạt sol khí tại Bạc Liêu. Để thực hiện điều này, trước hết chúng tôi xác định thời điểm bắt đầu gió mùa mùa hè - mùa mưa năm 2003. Sau đó, chúng tôi xác định sự suy giảm của $\mathrm{AOD}$ và sự thay đổi các thông số Angstrom sau các trận mưa ngày 1 và đêm ngày 3 sáng ngày 4 tháng 5 năm 2003. Kết quả cụ thể có thể tóm tắt như sau:

Thời điểm bắt đầu gió mùa mùa hè-mùa mưa trên khu vực Nam Bộ năm 2003 được xác định là ngày 4 tháng 5 . Trong khoảng thời gian này, trạm Bạc Liêu nghi được 3 trận mưa: trận thứ nhất, ngày 1 trong khoảng 11-13h với lượng mưa $4 \mathrm{~mm}$; trận thứ hai từ $20-21 \mathrm{~h}$ ngày 3 với lượng $7,5 \mathrm{~mm}$; và trận thứ 3 từ $3-5 \mathrm{~h}$ ngày 4 với lượng $5,5 \mathrm{~mm}$.

Những trận mưa đầu mùa năm 2003 làm giảm đáng kể giá trị của độ dày quang học sol khí. Sau 3 trận mưa, từ ngày 1 đến ngày 4 tháng 5 , độ dày quang học sol khí tại bước sóng $500 \mathrm{~nm}$ giảm từ 0.4 xuống 0.1. Các trận mưa đầu mùa cũng làm thay đổi phân bố kích thước của các hạt sol khí trong khí quyển. Cụ thể các hạt có kích thước lớn bị mưa cuốn trôi ngay từ trận mưa đầu tiên. Hệ số $\beta$ giảm từ 0,23 (ngày 30 tháng 4 ) xuống 0,07 (ngày 3 tháng $5)$ và 0,04 (ngày 5 tháng 5 ).

Sự chênh lệch của AOD, tại bước sóng $500 \mathrm{~nm}$, giữa tháng đầu mùa mưa và tháng cuối mùa khô, do ảnh hưởng của mưa đầu mùa, là 0.025. Tính trung bình từ năm 2003 đến năm 2009, AOD trong 4 tháng mùa khô (tháng 12, 1, 2 và 3 ) là 0.29 , và trong 4 tháng mùa mưa (tháng 6 , $7,8$, và 9$)$, là 0.19 .

Những kết quả trên đã chứng minh ảnh hưởng của mưa đầu mùa tới độ dày quang học và phân bố kích thước của các hạt sol khí. Tuy nhiên, đây chỉ là một trường hợp điển hình, còn nhiều vấn đề khác liên quan đến quan hệ giữa mưa và sol khí cần được làm sáng tỏ thêm như: quan hệ giữa tỷ lệ các phần tử sol khí bị cuốn trôi và cường độ của trận mưa? trong điều kiện bình thường thì khoảng bao lâu các phần tử sol khí có thể khôi phục lại như trước trận mưa?. 
Lời cảm ơn: Bài báo được hoàn thành với sự trợ giúp kinh phí của đề tài nghiên cứu cơ bản "Nghiên cứu khả năng dự báo ngày bắt đầu gió mùa mùa hè - mùa mưa trên khu vực Nam Bộ" thuộc quỹ Phát triển Khoa học Công nghệ Quốc gia (NAFOSTED) và đề tài nghiên cứu cơ bản định hướng ứng dụng: "Nghiên cứu đánh giá các đặc trưng cơ bản của sol khí "aerosol" và định hướng ứng dụng trong bảo vệ môi trường”. Trong bài báo có sử dụng số liệu AERONET của NASA và số liệu của NCEP. Tác giả xin bày tỏ lòng biết ơn đến các tổ chức trên.

\section{$T \grave{I} I L I \hat{E} U D \tilde{A} N$}

[1] Nguyễn Xuân Anh, Lê Việt Huy, 2008: Nghiên cứu aerosol qua trạm Bắc Giang và Bạc Liêu. Tuyển tập các công trình nghiên cứu vật lý địa cầu 2008, trang 307-320.

[2] Chung C.E., Ramanathan V., Kim D., Podgorny I.A., 2005: Global anthropogenic aerosol direct forcing derived from satellite and ground-based observations. Journal of Geophyical Research, Vol. 110, D24207, doi:10.1029/2005JD006356, 2005.

[3] Hồ Thị Minh Hà, Phan Văn Tân, 1999: Mô phỏng số trị ảnh hưởng của son khí carbon đen lên khí hậu khu vực Đông Nam Á và Việt Nam. Hội thảo gió mùa châu Á lần 2, 185-197.

[4] Lau K.-M., et al, 2008: The joint AerosolMonsoon Experiment: A New Challenge for Monsoon Climate Research. Bulletin of the American Meteorological Society, Vol 89, 369-383.

[5] Lau K.-M. and Kim K.-M., 2006: Observational relationships between aerosol and Asian monsoon rainfall, and circulation. Geophyical Research Letters, Vol. 33, L21810, doi:10.1029/2006GL027546, 2006.

[6] Qian W. and D.-K. Lee, 2000: Seasonal march of Asian summer monsoon. Int. J. Climatol., 20, 1371-1386.

[7] Ramanathan $V$., et al, 2005: Atmospheric brown clouds: Impact on South Asian climate and hydrologic cycle. Proc. Natl. Acad. Sci. USA, 102, 5326-5333.

[8] Saha A. and Moorthy K.K., 2004: Impact of Precipitation on Aerosol Spectral Optical Depth and Retrieved SizeDistributions: A Case Study. Journal of Applied Meteorology, Vol 43, 902-914.

[9] Pham Xuan Thanh, Fontaine B., Philippon $N$., 2010: Onset of the Summer Monsoon over the Southern Vietnam and its Predictability. Theor. Appl. Climatol., 99, 105-113.

[10] Wang B. and Lin Ho, 2002: Rainy Season of the Asian-Pacific Summer Monsoon. J. Climate, 15, 386-398.

[11] Zhang Y., et al, 2009: Impact of biomass burning aerosol on the monsoon circulation. Geophyical Research Letters, Vol.36, L10814, doi:10.1029/2009GL037180, 2009.

[12] Zhang Y., Li T., Wang B., Wu G., 2002: Onset of the Summer Monsoon over the Indochina Peninsula: climatology and interannual variations. J. Climate, 15, 3206-3221.

[13] WMO: Background Air Pollution Monitoring (BAPMON) Network Information Manual, TD-9789, September, 1990.

\section{SUMMARY}

\section{Impact of rainfall in summer onseting monsoon on aerosol optical depth in Bac Lieu}

\footnotetext{
Impact of rainfall in summer onseting monsoon on the Aerosol Optical Depth (hereafter AOD) and size distribution of aerosols elements were evaluated in the case of the rainy season in 2003 based on hourly rainfall data in Bac Lieu and AOD data from Aerosol Robotic Network (AERONET). First, we specify the onset of summer monsoon over the Southern Vietnam and the rainy days in the early rainfall season is also detected in 2003 from Bac Lieu rain gauge data. After that, effect of early season rainfall in 2003 on AOD and size distribution is evaluated by the decrease of AOD at $500 \mathrm{~nm}$ and the change of Angstrom parameters. Results show that the onset of the summer monsoon over the Southern Vietnam in 2003 is 4-May. At that time, we detected 3 rainy days from Bac Lieu rain gauge station data, it is 1, 3 and 4 with the rainfall is $4,7.5$ and 5.5 , respectively. The rains of early season rainfall in 2003 significantly reduced the aerosol optical depth. After 3 rainy days, AOD at $500 \mathrm{~nm}$ wavelength decreased from 0.4 to 0.1 . The rain in early season rainfall also changed size distribution of aerosols elements in the atmosphere. The aerosols elements have large size is swept away by the first rainy day. The $\beta$ decreased from 0.23 (30 April) to 0.07 (3 May) and 0.04 (5 May). The difference of AOD at $500 \mathrm{~nm}$ between the first month of rainfall season and the last month of dry season in period $2003-2009$ is 0.025 . The AOD average rainfall season and dry season is 0.29 and 0.19 , respectively. The AOD in $500 \mathrm{~nm}$ average of four dry months (Dec, Jan, Feb and Mar) is 0.29 and of rainy months (Jun, Jul, Aug, and Sep) is 0.19.
} 